\title{
The Effects of Experimentally Induced Changes in Ego States on Pronunciation Ability in a Second Language: An Exploratory Study
}

\author{
By Alexander Z. Guiora, Benjamin Beit-Hallahmi, Robert C. L. Brannon, \\ Cecelia Y. Dull, and Thomas Scovel
}

$\mathbf{I}^{\mathrm{s}}$ AN ATTEMPT to apply the methods of scientific inquiry to the rich but relatively elusive data that are generated in the clinical circumstance, a research strategy, termed transpositional research, has been proposed by Guiora. ${ }^{9}$ The first step in this strategy is the identification of another realm of behavior where the phenomena first observed in the clinical situation can also be assumed to exist. It is essential, however, that the behavior chosen for hypothesis testing lend itself readily to experimental manipulation and control. Thus, once a hypothesis generated in the clinical setting is tested out in the transposed realm, we can then hope to reapply the findings to the original circumstance.

For the past several years, Guiora has been engaged in the empirical study of the concept of empathy. The nonclinical behavioral realm selected for this study was the ability to authentically pronounce a second language.

In a series of publications, Guiora ${ }^{6,8,10}$ developed the proposition that empathy can be conceptualized as a comprehending modality alongside inference and intuition and offered the following definition: "Empathy is a process of comprehending in which a temporary fusion of self-object boundaries, as in the earliest pattern of object relations, permits an immediate emotional apprehension of the affective experience of another, this sensing being used by the cognitive functions to gain understanding of the other."

It is clear from the foregoing definition that empathic capacity is viewed as critically dependent upon the flexibility of the psychic processes which function to regulate self-object boundaries. The choice of authenticity of pronunciation as the behavioral realm for testing hypotheses concerning empathic capacity is based on the notion that pronunciation ability is profoundly influenced by the same underlying processes, namely, permeability of ego boundaries.

In a recent paper ${ }^{5}$ Guiora introduced a new concept: language ego. It was proposed that similar to the concept of body ego,${ }^{12}$ language ego is conceived as a maturational concept and likewise refers to self-representation with physical outlines and firm boundaries: "Grammar and syntax are the solid structure on which speech hangs, lexis the flesh that gives it body, and pronunciation its very core. Pronunciation is the most

From the Departments of Psychiatry and Psychology of the University of Michigan, Ann Arbor, Mich.

Alexander Z. Guiora, Ph.D.: Professor of Psychology, Departments of Psychiatry and Psychol. ogy, University of Michigan, Ann Arbor, Mich. Benjamin Beit-Hallahmi, Ph.D.: Psychologist, Counseling Center, University of Michigan, Ann Arbor, Mich. Robert C. L. Brannon, Ph.D.: Assistant Professor of Psychology, Brooklyn College, CUNY, New York, N. Y. Cecelia Y. Dull, M. A.: Research Assistant, Department of Psychiatry, University of Michigan, Ann Arbor, Mich. Thomas Scovel, Ph.D.: Chiengmai University, Chiengmai, Thailand.

The authors are or have been associated with the University of Michigan Personality Variables in Language Behavior Research Project. 
salient aspect of the language ego, the hardest to penetrate (to acquire in a new language), the most difficult to lose (in one's own)."5

The development of the language ego directly parallels that of general ego development. In the early stages of development the boundaries of the language ego are in a state of flux and, hence, pronunciation ability is quite malleable. One clear manifestation of this state of affairs is the child's relative ease in assimilating nativelike pronunciation in a foreign language. Once these boundaries become set, in terms of the degree to which they will be allowed to fluctuate under normal circumstances, the ability to approximate authentic pronunciation in a second language will be drastically reduced.

It is our contention that second-language learning in all of its dimensions exerts a very specific demand with regard to self-representation. Essentially, to learn a second language is to take on a new identity. Since pronunciation appears to be the aspect of language behavior most resistant to change, we submit that it is therefore the most critical to self-representation. Hence, we propose that the most sensitive index of the ability to take on a new identity, i.e., the degree of permeability of language ego boundaries, is found in the ability to achieve nativelike pronunciation in a second language. Considering that empathic capacity is also dependent upon the ability to partially and temporarily give up one's separateness of identity, we propose that individual differences in the ability to pronounce a second language should reflect individual differences in empathic ability.

Having laid out the theoretical framework for the hypothesis that flexibility of psychic processes is critical both to empathy and second-language pronunciation, we are in a position to chart an empirical investigation. The course that we have chosen is a multidimensional one which, if successful, provides a higher degree of validity than a single-dimensional approach. Essentially we are proposing that the approximation of nativelike pronunciation in a second language can be studied as developmental stages, stable differences in adults, and experimentally induced behaviors.

In two previous studies 11,18 we tested the hypothesis that empathic capacity is a significant variable in the ability to authentically pronounce a second language. In the pilot study, Guiora et al., ${ }^{5}$ using as the empathy measure the micromomentary expression (MME) procedure, a rank order correlation of +0.60 was found between this measure and pronunciation proficiency. A second study ${ }^{18}$ introduced refinements in the MME apparatus, an alternate projective measure of empathy and four independent measures of the facility of English-speaking subjects in learning authentically to speak a limited Japanese vocabulary. The results obtained in this study indicated that the MME and TAT scores combined with a measure of verbal intelligence accounted for more than half of the variance in language (pronunciation) performance, as indicated by a multiple correlation of $\mathrm{R}=+0.72$. A large-scale replication of the Taylor et al. study provided clear confirmation of the earlier findings. A multiple correlation of $R=+0.69$ (upper limit) was found between pronunciation performance and a series of empathy measures. ${ }^{7}$

The study to be reported here represents a different dimension of our multidimensional approach and deals with the experimental manipulation of what we have referred to as flexibility of psychic processes or permeability of ego boundaries. Given the evidence for the relationship between empathy and pronunciation ability and the assumption that flexibility of psychic processes is of the same critical importance to the latter as to the former, then alteration of that flexibility should produce alterations in pronunciation ability. 
Of the various means of producing an alteration of ego functioning, the most familiar and socially acceptable is alcohol. Most studies of the effects of alcohol on behavior are concerned with impairment of functions and performance and, indeed, there is evidence that alcohol impairs functioning at many levels. Yet, the proposal to be tested here is that alcohol in small amounts, such as those consumed by a careful social drinker, will facilitate the skill of pronunciation. Various theories have been proposed to explain alcoholism, ${ }^{16}$ but few of these are useful in explaining the behavior of social drinkers. As Kalin et al. ${ }^{14}$ stated, ". . . It is hard to believe that people drink in order to think, talk or act in an uncoordinated, inefficient way."

Vogel ${ }^{19}$ was apparently the first to suggest the theoretical possibility that certain aspects of performance may improve at low blood-alcohol levels. Soon thereafter Gaines $^{4}$ reported an improvement in performance on abstract thinking tests following moderate doses of alcohol; the results were attributed by the author to anxiety reduction. More recently it has been reported that small doses of alcohol seem to facilitate the production of associations ${ }^{17}$ and to bring about initial improvements in logical reasoning, followed by impairment with increasing dosage. ${ }^{2}$

There appears to be general agreement that alcohol in small doses does affect a variety of ego functions. The term most generally applied to this process is "lowering of inhibitions." Yet, in most studies the results of alterations of ego functions is interpreted as deleterious. The hypothesis tested in this study was that the ingestion of a small amount of alcohol will lead to an increase in the ability to pronounce a second language.

\section{METHOD}

Eighty-seven University of Michigan students served as subjects for the experiment. All were over 21 years of age and were informed in advance only that the experiment would involve responses to an alcoholic beverage. Half of the subjects were required to avoid intake of any food or beverage after lunchtime on the day of the experiment, which took place during the early evening. The other group of subjects was given the same instructions except that they were to eat a full-sized candy bar one hour before reporting to the laboratory and to bring the wrapper with them.*

Upon entering the laboratory the subjects were assigned to one of five treatment conditions based upon self-reported body weight and previously ascertained Scholastic Aptitude Test scores (obtained from university records). The purpose of the assignment procedure was to control the effects of body weight and general intellectual ability by equating the treatment groups on these attributes as nearly as possible.

The subjects were then asked to drink a "cocktail" presented by the experimenter. All such cocktails were served with cocktail napkins, in stemmed glasses, and were garnished with a cherry and a twist of lemon peel. A darkroom signal timer was set to allow exactly 10 minutes for the drink to take effect, and at the end of this period subjects immediately began the language test described below.

The "cocktail" ingested by each subject contained either zero, one, one and a half, two, or three ounces of ninety proof liquor. The four alcohol treatments consisted of varying amounts of a punch known for its deceptive potency. It is one half liquor (cognac, light and dark rum) and one half other ingredients, such as citrus juices. $\Lambda$ three-ounce serving thus contained one and a half ounces and so on.

The zero-liquor condition was designed to simulate a cocktail in order to hold constant the wide range of nonphysiological influences that normally attend the act of drinking a liquor. The subjects

\footnotetext{
*Adherence to these instructions was checked in a posttest questionnaire after the subjects had been paid for their participation. The subjects were asked to recall everything they had eaten since 12 noon, in a way suggesting that we expected everyone to have cheated a little. Several subjects were eliminated from the data analysis on the basis of food ingestion reported at this time.
} 
had been told that they would receive a cocktail, and the drink offered had all the accoutrements of one (ice-cold glass, garnishes, and the aroma of twisted lemon peel). In fact, it contained a nonalcoholic mixture made with brandy and rum flavorings, aromatic bitters, and a trace of cayenne pepper to simulate the taste and sensation of alcohol.

After ten minutes had elapsed the subjects were taken to a separate room and tested on two measures: the Standard Thai Procedure, which was developed by one of us to test ability to approximate pronunciation in an unfamiliar foreign language, and the Digit Symbol Test, a subtest of the Wechsler Adult Intelligence Scale. ${ }^{20}$

\section{The Standard Thai Procedure (STP)}

The STP was developed for the purpose of assessing second-language pronunciation ability and to be used uniformly in all our studies. The major concern in constructing the test was that of appropriateness of use with almost any population (regardless of age, education, and so on). It was felt that the test language should be one not commonly taught or studied in this country. In addition, it seemed important that the language be relatively easy for English-speaking subjects to pronounce, yet at the same time relatively distant, phonetically, from English. These considerations plus the practical constraint of the availability of native speakers experienced in evaluating pronunciation eventually led us to choose the Thai language.

The test consists of ten one-syllable contrastive items and six expansion drill series. Each expansion drill series is composed of four items beginning with a single syllable to which a second, third, and fourth syllable are added successively. An example of such a series follows:

$\begin{array}{ll}\text { Diagrammatically: } & \text { English Example: } \\ \mathrm{X} & \text { since } \\ \mathrm{XX} & \text { since swifts } \\ \mathrm{XXX} & \text { since swifts surpass } \\ \mathrm{XXXX} & \text { since swifts surpass swans }\end{array}$

Six such expansion drill series generated twenty-four of the total thirty-four test items.

The ten contrastive items are all of one syllable. Five of these items test for the five Thai tones using the same syllable. Two of the remaining five items contrast aspiration and nonaspiration; two more contrast vowel length; and the last tests for initial velar nasal sound.

The thirty-four test items are presented in the following order: sixteen one-syllable, six twosyllable, six three-syllable, and six four-syllable. It should be noted that while syllable difficulty increases with the progressive addition of syllables, there is a certain practice effect built in to the test due to the expansion drill series. By the time the subject reaches the four-syllable items, only the fourth syllable is unrehearsed, while the first syllable has previously been uttered three times, the second syllable twice, and the third syllable once.

Presentation: The STP is an aural-oral test; each of the thirty-four test items are recorded on a master tape. The voicer is a female native Thai speaker. Between each utterance there is a pause of about 4 seconds during which the testee is required to imitate the preceding utterance. A two-track recording is made during this test, with the stimuli recorded on one track and the subjects' responses on the other. The total amount of time involved in administering this test is approximately four and a half minutes. The test tape is $2 \frac{1}{2}$ minutes long, and instructions require about 2 minutes.

Evaluation: A total of twenty-eight pronunciation units in the test are scored. Sixteen of these are elements consisting of a single syllable; these are evaluated for one of the following features: tone, vowel length or combination, initial or final consonant. The remaining twelve items scored are the first and last syllables of the four-syllable utterances. Rating of these twelve syllables is general; that is, tone, vowel, and consonant quality are not isolated parameters as in the first sixteen monosyllabic test items.

Scores for the STP are developed in the following manner. Each of the twenty-eight pronunciation units is given a rating on a scale of one to three. (1) Poor-strongly marked with foreign accent or almost unintelligible; (2) fair-passable and not likely to cause any misunderstanding although not completely nativelike; and (3) good-quite nativelike or close to nativelike pronunciation.

Data tapes for all subjects are identified by code numbers and are evaluated independently and simultaneously by a team of three experts in the Thai language. A subject's total raw score is the 


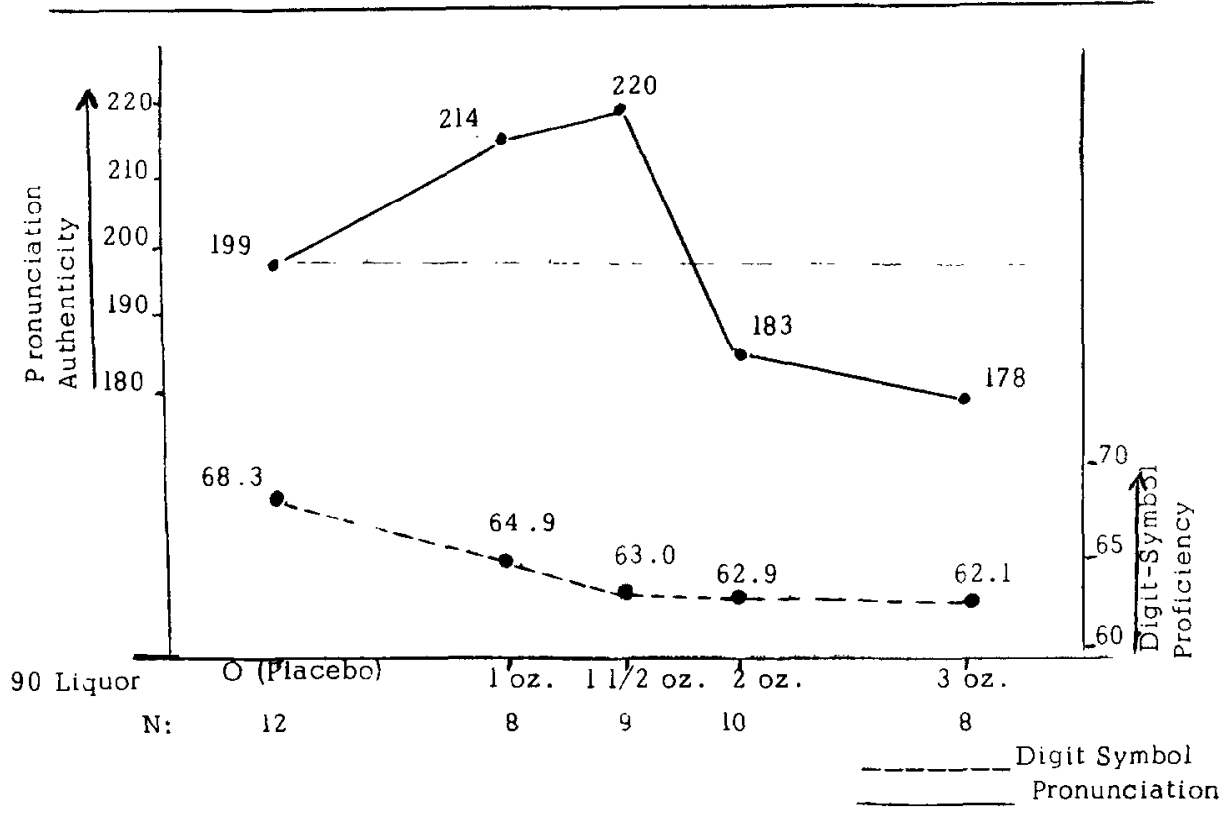

Fig. 1. Mean pronunciation and digit-symbol performance at five levels of alcohol consumption after ingestion of sugar.

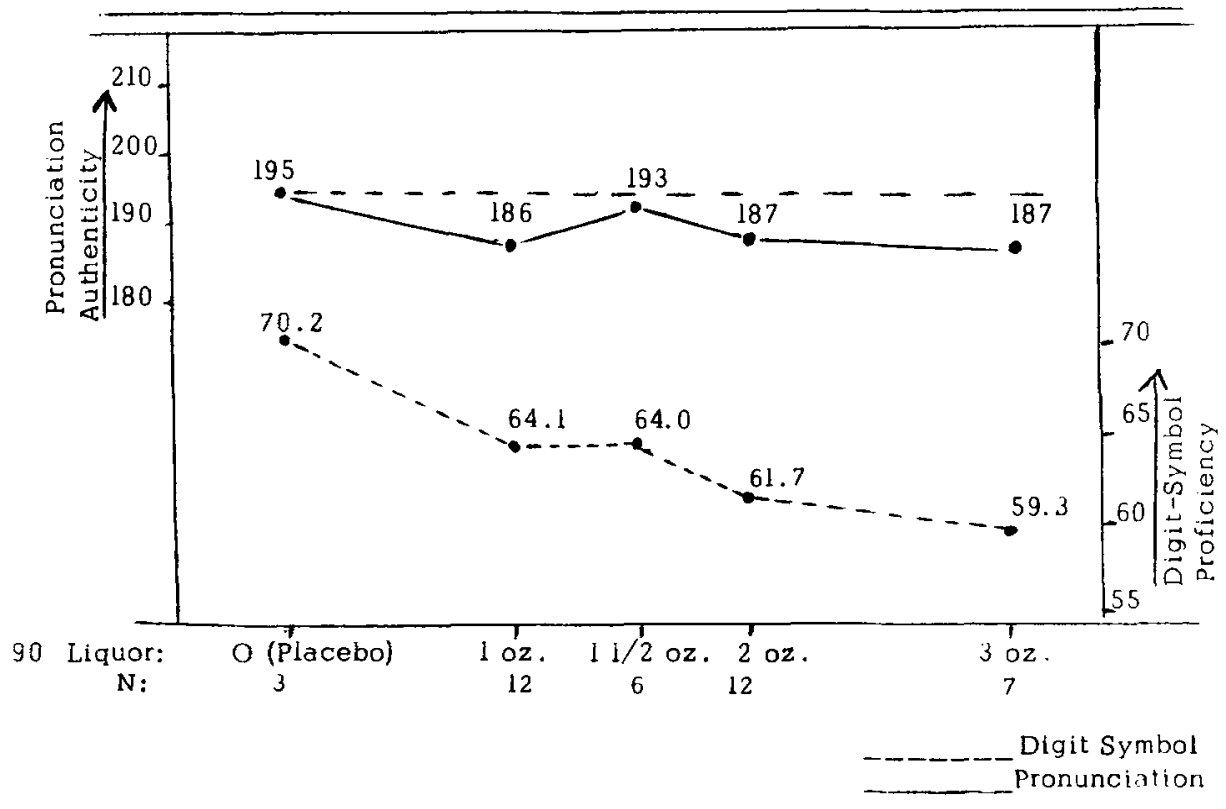

Fig. 2. Mean pronunciation and digit-symbol performance at five levels of alcohol consumption on totally empty stomach. 
sum of each of the three rater's twenty-eight evaluations; thus, the maximum score is 252 points. Interjudge reliability on these ratings average $r=0.81$; the homogeneity of total scores based on three raters (coefficient alpha) reached a highly acceptable 0.89 .

\section{RESULTS}

Mean performance scores on the test of pronunciation authenticity and the DigitSymbol Test after sugar ingestion are depicted in Fig. 1. The upper curve, representing mean pronunciation scores for each treatment, indicates a highly significant effect due to the amount of alcohol ingested $(F=2.6,4,42 ; \alpha \leqslant 0.01)$. Considering components of this curve separately, the one and one and a half ounce conditions are significantly higher than the control condition of no alcohol $(t=4.47 ; \alpha \leqslant 0.01)$; while the twoand three-ounce conditions taken together are significantly lower than the control $(r=4.11 ; \alpha \leqslant 0.01)$.

The lower curve in Fig. 1 depicts the performance of these same subjects on the Digit Symbol Test. The slight decline in performance indicated however, was nonsignificant $(F=1.0 ;$ N.S.).

Results for the second group of subjects, those who consumed varying amounts of alcohol on a totally empty stomach, are shown graphically in Fig. 2 . On both the pronunciation and the intelligence measures there was no significant effect associated with the amount of alcohol consumed $(\mathrm{F}=1.0 ; \mathrm{N} . \mathrm{S}$.). Although the groups receiving any amount of alcohol actually did slightly worse than the control group on both tasks, this trend should not be interpreted on the basis of the available data.

\section{DISCUSSION}

The results of this study are interpreted as confirming the hypothesis that the ingestion of small amounts of alcohol, under certain circumstances, does lead to increased ability to authentically pronounce a second language.

The present study was in many respects exploratory, in the sense that we had no means of stating precisely what amount of alcohol would produce the predicted effect. It seemed most reasonable to assume that an extremely small quantity of alcohol would produce no effect; and that at some point, perhaps not far above the point of maximum facilitation, the results would show a decline in performance. The correct dosage therefore was an empirical question that we sought to answer by using five different quantities of alcohol. Sugar (S) and nonsugar (NS) conditions were added as a further refinement of the design. It was felt that possibly even a small amount of alcohol ingested in a totally empty stomach would prove to be too strong.

While the STP performance curve for the NS condition does appear to show a general decline with consumption of any amount of alcohol, these findings were not significant. For the $\mathrm{S}$ group, however, the results are qualitatively different. It would appear that in the present data a maximal increase in performance on the STP occurs with ingestion of approximately one to one and a half ounces of alcohol and when a small amount of sugar has been ingested prior to alcohol consumption.

The results for the Digit Symbol Test, a well-known measure of overall mental functioning* (cognitive, psychomotor, memory, i.e., integrated ego functioning), lend

*The Digit Symbol Test is one of the oldest and best established of all psychological tests. ${ }^{20}$ It is a quick and fairly accurate measure of the subject's intellectual capacity. It correlates with WAIS Full Scale Scores +0.63 to +0.69 . 
definite support to the notion that we are dealing with a very specific effect. The fact that performance on this test was literally unaffected by small quantities of alcohol while the STP showed a rise and then a drop in performance leads us to conclude that pronunciation ability is apparently critically influenced by a psychological variable that can be successfully isolated from the larger web of ego functions.

Our previous studies indicated a positive relationship between empathic capacity and the ability to pronounce a second language. The prediction of this relationship was based upon a theoretical model that postulated that these two behaviors will vary as a function of the degree of flexibility of underlying psychic processes or permeability of ego boundaries. One specific ego function that is positively related to the permeability of ego boundaries is the ability to temporarily give up one's separateness of identity from others. It is this particular function that is of central importance to the empathic process and to pronunciation ability as well.

The findings of the present study confirm the previous evidence of a relationship between empathy and authenticity of pronunciation of a second language and, more important, support our theories about the nature of the underlying processes.

One alternative explanation for the findings concerns the possibility that the alcohol consumed under the condition produced an alteration in short-lem memory. However, there is no evidence from previous work in the area that would lead us to suspect that such an explanation is plausible. Jellinek and McFarland ${ }^{13}$ summarized the research on short-term memory changes under the influence of alcohol and concluded that alcohol causes an overall moderate impairment of short-term memory. Davis et al. ${ }^{3}$ and Carpenter ${ }^{1}$ also report findings that show that alcohol affects shortterm memory adversely.

There is a great deal of evidence that small quantities of alcohol are found to minimally or negatively effect performance on tasks that demand highly integrated ego functioning. If we are correct in viewing the lowering of inhibitions via alcohol as operationally inducing a state of greater permeability of ego boundaries or the ability to partially and temporarily give up one's separateness of identity, then evidence of an enhancement of certain skills under particular conditions of alcohol ingestion is, we believe, evidence that individual differences in these skills are related to basic differences in the flexibility of psychic processes.

There are several important implications of these findings. First of all, while the development of the STP is still in the exploratory stages, we believe that it offers definite potential as an indirect measure of empathic ability. In addition to its simplicity and ease of administration and objectivity of scoring, it appears to have a high level of construct validity.

Second, we believe that the findings lend conclusive support to our view that pronunciation ability is indeed a unique feature of second-language learning in that individual differences in that skill appear to be directly related to flexibility of psychic processes as contrasted with highly integrated ego functioning which plays a major role in learning and manipulating grammar, syntax, and vocabulary.

Finally, and additionally, we believe that this study can be seen as supporting the notion of an early positive stage in intoxication. The lack of a significant change in Digit Symbol performance indicates, however, ${ }^{15}$ that this so-called positive stage is limited to certain specific functions. We would suggest then that for those ego functions, such as empathy, that are positively related to increased permeability of ego 
boundaries and the accompanying need for consistency and use of established behavior patterns, small amounts of alcohol should produce a facilitating effect.

In conclusion, in the present study alcohol produced a temporary change in ego boundaries, in the form of greater permeability, and thus enhanced the ability to approximate nativelike pronunciation of a second language. This lends strong experimental support to the view ${ }^{\mathbf{s}}$ that permeability in the language ego (specifically in pronunciation) will be a reflection of the permeability of ego boundaries in general and of empathic capacity in particular.

\section{ACKNOWLEDGMENT}

The authors gratefully acknowledge the assistance of Mrs. Ronna Hoy and Dr. Neal Kalter in the execution of this study.

\section{REFERENCES}

1. Carpenter, J. A.: Effects of alcohol on some psychological processes: a critical review. Quart. J. Stud. Alcohol. 23:274, 1962.

2. -, Moore, O. K., Snyder, C., and Lisansky, E.: Alcohol and higher-order problem solving. Quart. J. Stud. Alcohol, 22:183, 1961.

3. Davis, P. A., et al: The effects of alcohol upon the electroencephalogram (brain waves). Quart. J. Stud. Alcohol, 1:626, 1941.

4. Gaines, J.: The temporary effects of varying amounts of alcohol on abstract thinking efficiency. Dissertat. Abstr. 20:2918, January 1960.

5. Guiora, A. Z.: Construct validity and transpositional research: toward an empirical study of psychoanalytic concepts. Compr. Psychiat. In press.

6. - : On Clinical diagnosis and prediction. Psychol. Rep. 17:779, 1965.

7. - ; with the assistance of Brannon, R. C. L., and Dull, C. Y.: The role of personality variables in second language behavior. Final Report. Ann Arbor, Mich., 1971. Defense Language Institute.

8. - : Toward a systematic study of empathy. Compr. Psychiat. 8:5, 1967.

9. - : Transpositional research in the clinical process. Compr. Psychiat. 11:6, 1970.

10. - Bolin, R., Dutton, C., and Meer, B.: Intuition-a preliminary statement. Psychiat. Quart. Suppl. 39:1, 1965.

11. -, Lane, H. L., and Bosworth, L. A.: An exploration of some personality variables in authentic pronunciation of a second language.
In H. L., Lane, and Zale, E. M. (Eds.); Studies in Language and Language Behavior. 1968, p. 463 .

12. Hartmann, H.: Essays on Ego-Psychotogy-Selected Problems in Psychoanalytic Theory. New York, International Universities, 1964.

13. Jellinek, E. M., and McFarland, R. A.: Analysis of psychological experiments on the effects of alcohol. Quart. J. Stud. Alcohol. $1: 272,1940$.

14. Kalin, R., McClelland, D. C., and Kahn, M.: The effects of male social drinking on fantasy. J. Personality Soc. Psychol. 1:441, 1965.

15. Kastl, A. J.: Changes in ego functioning under alcohol. Quart. J. Stud. Alcohol. 30 (Part A):371, 1969.

16. McCord, W., and McCord, J.: Origins of Alcoholism. Stanford, Stanford University Press, 1960.

17. Nash, Harvey. Alcohol and Caffeine: A Study of Their Psychological Effects. Springfield, Ill. Thomas, 1962.

18. Taylor, L. L., Guiora, A. Z., Catford, J. C., and Lane, H. L.: The role of personality variables in second language behavior. Comp. Psychiat. 10:463, 1969.

19. Vogel, M.: Low blood alcohol concentrations and psychological adjustment as factors in psychomotor performance. An exploratory study. Quart. J. Stud. Alcohol. 19:573, 1958.

20. Wechsler, D.: The Measurement and Appraisal of Adult Intelligence. Baltimore, Williams \& Wilkins, 1958. 